\title{
Hybrid Micro-Grid Experimental Application in Tanzania
}

\author{
M. S. Carmeli*, M. Mauri*, C. Brivio**, P. Guidetti**, S. Mandelli**, M. Merlo**, R. Perini**, \\ G. Marchegiani ${ }^{\circ}$, D. Rosati $^{\circ}$ \\ *Politecnico di Milano, Dipartimento di Meccanica, Via La Masa 1, 20156, Milano, Italy \\ **Politecnico di Milano, Dipartimento di Energia, Via Lambruschini 4, 20156, Milano, Italy \\ ${ }^{\circ}$ MCM Energy LAB ,Via Durando 38/A, 20158 Milano, Italy
}

\begin{abstract}
This paper is intended to introduce the project Energy4Growing that aims at studying and setting up a hybrid micro-grid to supply power to a school in rural Tanzania. It describes the results of the early project actions which concerned in: (i) analysing the actual school power supply system through locally metered data; (ii) developing the first step of a new electro-mechanical model which addresses the simulation of operation and dynamics within an off-grid power system; (iii) validating the new model. In particular the paper focuses on describing the development and the first step implementation of the new modelling approach which address: (i) voltage and frequency analyses over medium term period by means of simplified electromechanical models of power sources and power electronics, (ii) the analysis of different dispatch strategies and their consequence on voltage and frequency trends, (iii) the effects of dispatch strategies on the energy performances of particular components such as battery bank or dump loads. The new approach has also been applied in modelling the current school power supply system.
\end{abstract}

Index Terms - Off-grid system, renewable energy, rural electrification, data meter, simulation.

\section{INTRODUCTION}

During the last decade a lot of efforts have been put into promoting the access to electricity to those millions of people living in rural un-electrified areas of Developing Countries (DCs). Despite the global interest, the progress of electrification rates in such areas is very limited and, according to the IEA projections in 2030, still about 1 billion people in DCs will lack access to electricity [1]. Besides evident economic constraints, also lack in appropriate and replicable technical solutions contributes in hindering the process of electrification. As regards this issue, $\mathrm{R} \& \mathrm{D}$ activities in off-grid power systems based on renewable energies (RE), which are often the most proper option for rural electrification [2]-[4], should also focus on solutions which (i) can easily adapt to the extremely different local contexts thus reducing capital costs; and (ii) can have output for implementation in developed countries thus expanding market opportunities. In authors opinion, efforts should be concentrated on micro-grids (MGs) which can achieve better results in terms of costs, efficiency and environmental benefits, satisfying also the demanding requirements for security, quality, reliability and availability of power supply [5]. MGs for rural electrification in DCs are intended to operate off-grid with the possibility of future main grid integration; indeed, in a bottom-up approach, MGs can work as building blocks for future system expansion [6]-[8].

In this context, the project Energy4Growing (E4G), promoted by a research group of the Politecnico di Milano, aims at studying, developing and setting up an off-grid power system to supply electricity to the secondary school of Ngarenanyuki, a rural village in Northern Tanzania (Fig. 1). Specifically, the project investigates a hybrid MG architecture suitable to interface RE technologies and energy needs in the most reliable way while exploiting advanced regulations and control techniques. The hybrid MG will combine the power generation systems already available in the school with the installation of a new apparatus made of PV panels and lead-acid battery bank together with an Interface Converter.
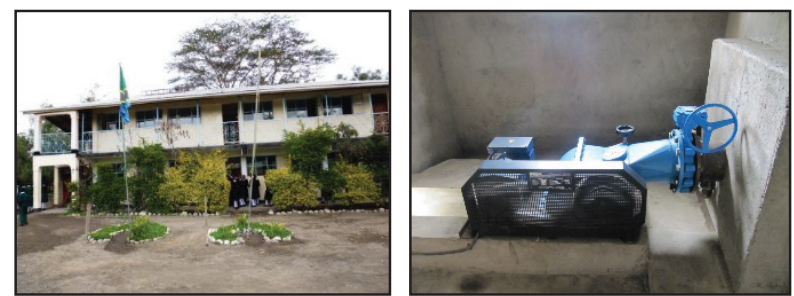

Fig. 1. Ngarenanyuki Secondary School (TZ) - Banki turbine generator.

The local energy scenario addressed by the project is characterized by the following elements:

- The main power source of the school is a run-off-river Micro hydropower plant (MHP) based on a $3.2 \mathrm{~kW}$ Banki turbine (Fig. 1) coupled with 1-phase brushless synchronous generator $(230 \mathrm{~V}, 50 \mathrm{~Hz})$.

- The water flow to the turbine is diverted from a stream, which is managed by local farmers. Therefore, water availability is highly variable during the day and according to the season, hence several blackouts occur.

- The frequency regulation is based on a $4 \mathrm{~kW}$ dump load, which dissipates the excess power in air.

- A $5 \mathrm{~kW}$ petrol generator is used when the MHP plant is off and only for important reasons.

- The power supply is managed in the control room by means of a toggle switch that permits to select the power source, while a group of breakers permits specific loads to be connected/disconnected manually.

- A first estimate of the school consumptions was carried out by local staff. Considering the actual appliances the daily load was calculated at around $70 \mathrm{kWh}$. While, 
considering the use of new further devices (ex-post the project intervention) at about $100 \mathrm{kWh}$ a day.

In this context, this paper describes the results of the early project actions which concerned (i) the analyses of the local data gathered by means of a specific metering campaign in order to have a comprehensive understanding of the school power supply system operation, (ii) the development of a new modelling approach for the simulation of the functioning of off-grid power systems, and (iii) the validation of this approach by means of the metered data. An example based on modeling with MATLAB $^{\circledR}$ Simulink $^{\circledR}$ of the current configuration of the run-off-river MHP plant and employing the metered data exemplifies the setup and potential of this approach. Our aim in developing off-grid power systems modelling based on this new approach is to contribute in improving the design process of these systems in order to facilitate the replicability of rural electrification interventions.

\section{ON FIELD METERED DATA ANALYSIS}

The first estimate of school electricity consumptions allowed the gathering of early information; however, it also suggested the need to locally meter load data in order to better understand the power supply and consumption pattern (i.e. daily load and power profiles) and hence to proceed properly in the design process of the hybrid MG. To this purpose, two meter instruments have been used:

- X-Meter: a multi-purpose network analyzer. Used to measure the electrical characteristics of the load consumption. So far, the device has recorded 120 days between June and December 2014 with 15 minutes average data saving.

- Efficiency Terminal: a portable network analyzer. Used for gathering more precise data about the whole power supply system (i.e. turbine, dump loads and user loads). The device has been installed during a specific on-site mission in October 2014 and has recorded five partial days with 1-minute average data saving.

Here below analyses relating to (i) the load consumption, (ii) the quality of service (e.g. frequency and voltage), and (ii) the functioning of the current power supply system, are presented according with the features of the two instruments.

\section{A. Load Analysis}

Fig. 2 shows the discrete probability distribution of the daily energy consumption over the 120 days monitored by the X-Meter. The values range from a few $\mathrm{kWh}$ to about $25 \mathrm{kWh}$ stressing a strong difference when compared with the average estimated daily load $(70 \mathrm{kWh})$. This is not surprising if the analysis is contextualized in rural areas of DCs, where people's energy needs are always limited by the lack of resources due to unreliable power systems. In this particular case, the high variability of the water source on a daily basis limits the daily availability of energy.

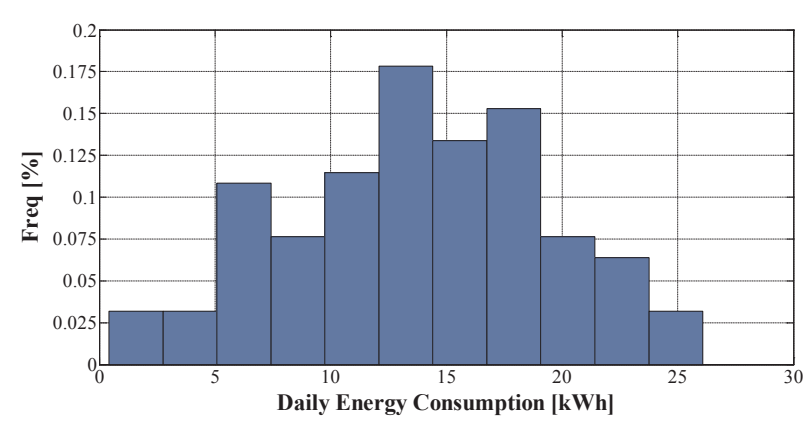

Fig. 2. Discrete probability distribution of daily consumptions.

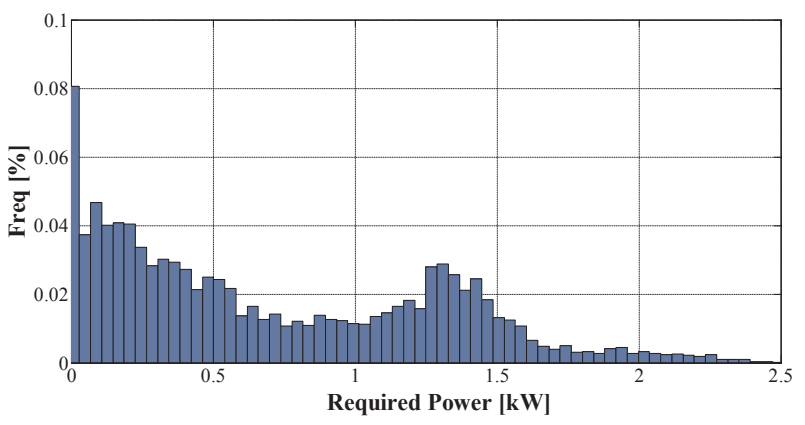

Fig. 3. Discrete probability distribution of the required power.

In Fig. 3 the discrete probability distribution of the required power is presented. The fact that there is more than one peak in the graph could be explained by a superposition of different probability distributions. Indeed, the operation of the system (and the consumption habits of the users of the school) varies in time due to different factors:

- The unpredictability of agricultural activities upstream of the school which causes the irregularity of the available power from the MHP.

- The different activities carried out in the school between weekdays (Mon-Fri) and weekend (Sat, Sun).

- The different activities carried out in the school throughout a day (morning, afternoon, evening, night).

As a consequence, the 120 load curves which have been metered by the X-Meter, do not show an average trend which trace a typical load curve from the school.

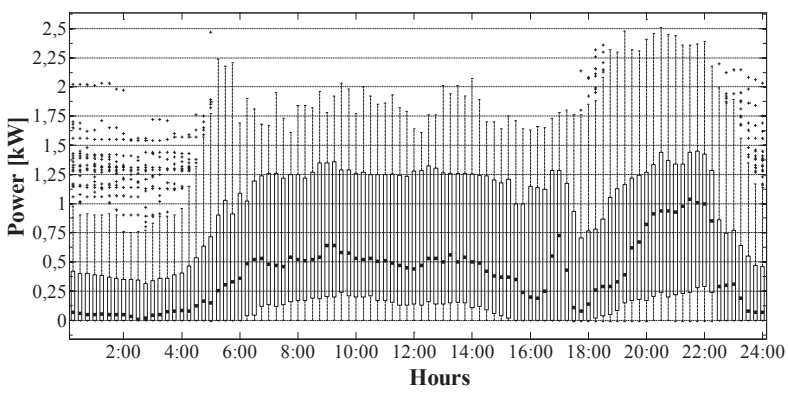

Fig. 4. Boxplot of the daily power consumption.

In support of this argument, we report the Tukey boxplot of the metered load values throughout length of the day (Fig. 4). At each hour of the day the power loads ranges from $0 \mathrm{~kW}$ to values above $2 \mathrm{~kW}$. The spacing 
between the different parts of the box confirms a highly degree of dispersion. This suggests again highly irregular water source availability on an hourly basis.

\section{B. System Voltage and Frequency Analysis}

Fig. 5 and Fig. 6 show the discrete probability of frequency and voltage in power quality (i.e. acceptable ranges: $50 \mathrm{~Hz} \pm 5 \%, 230 \mathrm{~V} \pm 10 \%$ ) over the 120 days interested by the metering activity. The graphs admit in both cases two maxima. This can be explained considering that there are two operating modes: one due to the MHP, with values close to the nominal ones $(49.9 \mathrm{~Hz}, 235-238$ $\mathrm{V})$, and the other one due to the diesel generator, which works at higher frequency $(52-53 \mathrm{~Hz}, 220 \mathrm{~V})$. Thus, it is worth emphasizing that in normal operation the frequency of the power supply proves to be quite stable at $50 \mathrm{~Hz}$. The same cannot be said in case of turbine overload where the metered frequency decreases to values which stay beyond the limits for power quality, as deeply investigated in the next section.

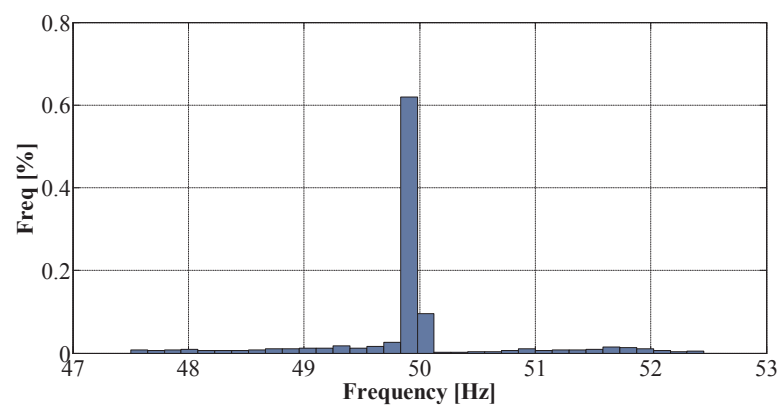

Fig. 5. Discrete probability distribution of frequencies.

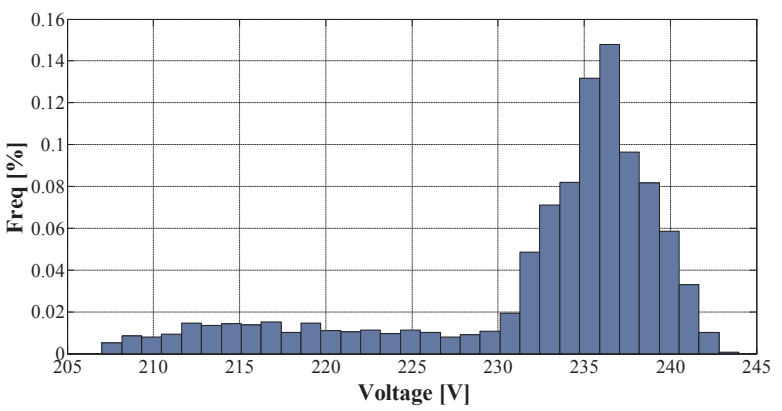

Fig. 6. Discrete probability distribution of voltages.

\section{Power Supply System Analysis}

Finally, we present the data collected by means of the Efficiency Terminal, which clearly depict the current power supply system functioning. Fig. 7 shows the power flows with 1-minute average data storing metered during the 20 of October 2014. As expected, the dump loads (brown line) keep the balance between the synchronous generator power production (blue line) and the load consumption (green line).

Looking at the metered data for this specific day, some consideration can be made:

- The MHP profile is constantly above the load power consumption profile. It could not be otherwise since the MHP is the only power source (the petrol generator was not operated during this day).
- Fig. 7 shows two periods in which clearly the water flow has been reduced and hence the power from the Banki turbine has decreased. The load is consequently forced to follow the same variation (causing some load rejection) and this fact is reflected also in the frequency profile (red line) which goes down due to the turbine overload. Probably, without this inconvenience, the desired load would have been about $1.5 \mathrm{~kW}$ constant.

- The frequency stability in normal operation (generation $>$ loads) is preserved to the detriment of dissipated energy by the dump loads.

The last two points suggest the opportunity to add an energy storage system. For instance, a battery bank can be operated in order to save the dissipated power and use it to fulfil the desired load when the MHP power is not enough.

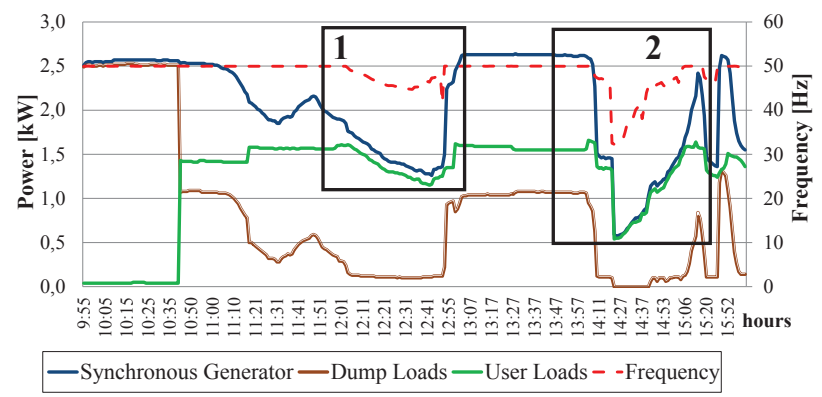

Fig. 7. Metered power flows and frequencies of October 20, 2014 for the actual power supply system of the school.

Nevertheless, addressing these aspects is not straightforward. For instance, due to the behavior of the dump loads, probably the battery bank (included in the new apparatus) will experience shallower but more frequent charge/discharge cycles thus decreasing its lifetime. Moreover, since the battery bank will not be intended to act in controlling the system frequency, it is quite important to analyze the power flows, in order to optimize the system control logics aiming at the longest lifetime while preserving the quality of the service. Therefore, several analyses are required to design properly the E4G hybrid MG. Moreover, modelling the existing plant could allow preliminary analyses towards the new development of the system.

\section{A NEW APPROACH FOR ELECTRO-MECHANICAL OPERATION AND DYNAMICS ANALYSIS}

When dealing with off-grid power system design, several analyses that join issues of sizing, optimized dispatching strategies, and quality of the power supply are required. In particular, it is necessary to simulate the system behaviour in order to improve reliability and stability performances during the design phase.

Reliability of a power system refers to the ability to supply adequate electric service on a nearly continuous basis, with few interruptions (i.e. loss of load) over an extended time period. Stability refers to the continuance of intact operation following a disturbance, and it depends on the operating condition and the nature of the physical disturbance. The two performances are quite different in particular regard of the time span necessary to quantitatively characterize them [9]: 
- Reliability is a function of the time-average performance of the power system; it can only be judged by considering the system's behaviour over an appreciable period of time.

- Stability, on the other hand, is a time-varying attribute which can be judged by studying the performance of the power system under a particular set of conditions in a relatively small period of time.

With respect of this main difference, in the scientific literature two main types of analyses are typically carried out in order to address respectively the above two performance characteristics: energy analyses and power system stability analyses:

- Energy analyses [10]-[15] aim at identifying the main component sizes (i.e. rate power of generators and storage capacity) with an energy planning and/or a technoeconomic approach. These analyses study the system reliability throughout its lifetime considering the local conditions and constraints. They are typically based on the steady-state solution of the energy balance between energy sources and consumer loads over a specific time-step, and considering the features of the system components. The length of the time-step can usually vary from day-to-day to one-minute (according to the desired accuracy), and analyses are performed throughout a year. A typical tool that embraces the main features of the energy analyses is HOMER $^{\circledR} \quad$ [16]-[18]. Recently multi-objective optimizations and multi-criteria decision making have been increasingly employed in order to embrace also environmental and social parameters in the planning and/or feasibility analyses [19]-[21].

- Power system stability analyses [22]-[28] take into account that a power system is a highly nonlinear system that operates in a constantly changing environment (i.e. loads and generators outputs, when based on RE, change continually). The main objective is to address the study of power system employing physical quantities which can be measured (e.g. current and voltage) in order to identify the key factors that contributes to instability and hence to devise methods for improving stable operation. To facilitate the task, the classification of power system stability is exposed in Fig. 8. It splits depending on (i) the main system variable where instability can be observed, (ii) the size of the disturbance considered, (iii) the time span that must be taken into consideration in order to assess stability. In any given situation, however, any form of instability may not occur alone and this is particularly true in highly stressed or small-size power supply systems. Nevertheless, distinguishing between different forms is important in applying suitable analysis tools. These analyses are based on circuit models of the components and on the solving of the related equations within the continuous time-domain. They are typically carried out for short intervals (from few seconds to some minutes) in order to study the developments of the monitored electrical quantities (mainly voltage and frequency) verifying the proper system functioning under particular circumstances.

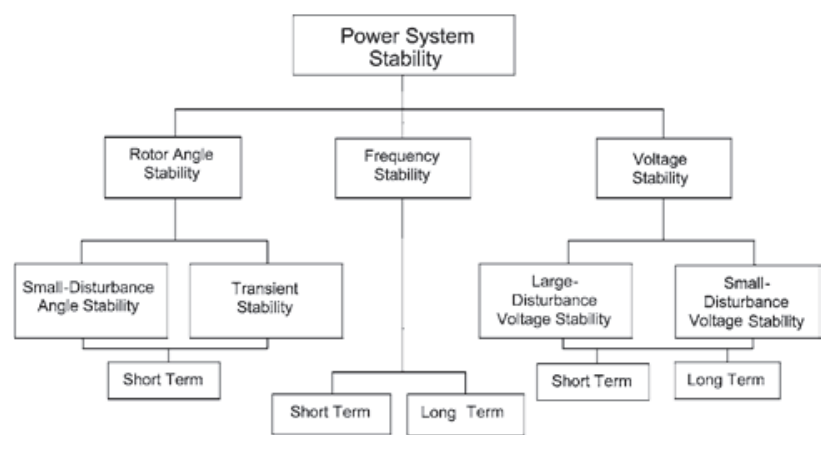

Fig. 8. Classification of power system stability.

In this framework, and given our experience with the E4G project, it will be newsworthy to address some aspects which are not appropriately addressed both by energy and power system stability analyses:

- Concerning energy analyses: even when physical quantities are employed in system components modelling, systems are studied with steady-state numerical simulations without considering the consequences they have on system control and hence on stability issues. These aspects can affect the size as well as the lifetime of the components especially when systems include rotating machines together with RE generators with power converters, and electrochemical storage. For instance, frequency stability problems in small off-grid systems are often associated with insufficient generation capability or poor resources coordination.

- Concerning power system stability analyses, they do not provide elements to optimize the sizes of the main components as regards system lifetime and they are too heavy when addressing issues that occur over longer periods (i.e. battery charge/discharge cycle, system control strategies, etc.).

In order to address the above mentioned issues, in this paper a new approach to system modelling that aims at balancing the limits and integrating the results of the already available energy and power system stability analyses is introduced. The objective of the new approach is to develop an off-grid power system simulation model capable of:

- Working over medium term period (i.e. days) with typical time-steps of power system stability analyses.

- Embracing simplified electrical models of power sources and power electronics in order to address at least voltages and frequencies trends analyses.

- Embracing simplified models of system control units in order to address the analysis of different control strategies.

- Considering the effects of the previously mentioned aspects on the performances of particular components such as battery bank or dump loads.

The approach will adopt classical mathematical models for generators and load representation. In fact, since the approach proposed is designed in order to fit with the DCs scenarios, the adoption of more detailed models does not lead to a more complete/reliable analysis due to the lack of information about generators, loads etc. 


\section{A THEORETICAL ELECTRO-MECHANICAL MODEL ABLE TO DESCRIBE THE ACTUAL POWER SUPPLY SYSTEM}

Hereafter we detail the description of the implementation of the new approach in developing a first step model for the current power supply system of Ngarenanyuki Secondary School (MHP and dump loads). For each of the modelled component (i.e. the synchronous generator, the dump loads and the user loads) we introduce the concepts and logics behind the modelling phase, and then we carry out a first implementation of the system model in MATLAB $^{\circledR}$ Simulink $^{\circledR}$ by means of the Simscape-SimPowerSystem library.

\section{A. Synchronous generator model}

Under steady-state conditions, there is equilibrium between the input mechanical torque and the output electromagnetic torque of each generator, thus the speed remains constant. If the system is perturbed, the equilibrium is upset, resulting in acceleration or deceleration of the rotors of the machines according to the laws of motion of a rotating element. This can be exhaustively analysed by a $7^{\text {th }}$ order model in the Park variables. However, in accordance with the previously mentioned targeted features of the new approach, the $7^{\text {th }}$ order model is simplified by considering the electromagnetic dynamics faster than the mechanical ones. Consequently, electro-magnetic variables are supposed to change according to steady-state behavior.

Therefore, taking into account the real plant at Ngarenanyuki and according to the new approach, the simplified electro-mechanical model of the synchronous generator in MATLAB ${ }^{\circledR}$ Simulink $^{\circledR}$ is based on the wellknown swing equation (1). This accounts for changes in power injections from load, dump loads and engine $\left(P_{\text {gen }}-\right.$ $\left.P_{\text {load }}-P_{\text {dump }}\right)$ that results in change in the angular velocity $(\omega)$. Finally, we model the synchronous generator driven by the Banki turbine as an ideal voltage source with constant amplitude (2) driven by the swing equation.

$$
\begin{aligned}
& J \cdot \omega \cdot p \cdot(d \omega / d t)=P_{\text {gen }}-P_{\text {load }}-P_{\text {dump }} \\
& V=230 \cdot \sqrt{ } 2 \cdot \sin (\omega \cdot t)
\end{aligned}
$$

\section{B. Dump loads model}

In an off-grid power system special attention must be paid to the frequency stability, as it is not guaranteed like in a high meshed grid. The system frequency can be maintained constant by eliminating the unbalance between generations and load consumptions.

Act on the generation side means to use conventional speed governors, which use electronics to sense changes in speed in order to control the resource exploitation (e.g. the water flow admittance in a MHP). Nevertheless, the generation control mechanism is typical not used in rural electrification interventions when the power ratings of offgrid systems are less than $100 \mathrm{~kW}$. Indeed in these cases, the cost of such a governor usually exceed the cost of the generator itself [29]-[31]. For this reason, uncontrollable prime movers are preferred, requiring thus to act on the load side so that the generator output power is held constant despite variations of the user loads. The different strategies which can be adopted in this direction are: dump load control, priority switched-load control, flywheel, superconducting magnetic energy storage systems, and battery energy-storage systems [32]-[34].

Over the last two decades, especially dump loads in the form of electronic load controllers (ELC) have spread. The basic concept any ELC uses is measuring the prime mover speed and compensating the variation in the user load by automatically varying the amount of power dissipated in a resistive load. This keeps the total load just right to attain the correct speed and to generate stable frequency. There are several advantages of ELC:

- The use of simpler and cheaper prime mover with less moving part.

- Less expensive than equivalent flow control governor.

- High reliability and low maintenance.

- ELC can be fitted at any point in electrical system.

The two most commonly employed techniques used for ELC are [35]:

- The phase delay action: where the dump load comprises a permanently connected single resistive load. As a result of the detection of a change in the user load, a power electronic switching device adjusts the average voltage applied to the dump load, and hence the power dissipated. However, this technique introduces harmonics causing overheating of electrical equipment connected to the system.

- The binary load action: where the dump load is made up from a switched combination of separate resistive loads. In response to a change in the consumer load, a switching selection is made to connect the appropriate combination of resistive load steps. During transitions, full system voltage is applied to the new fraction of the dump load and hence harmonics are not produced at all.

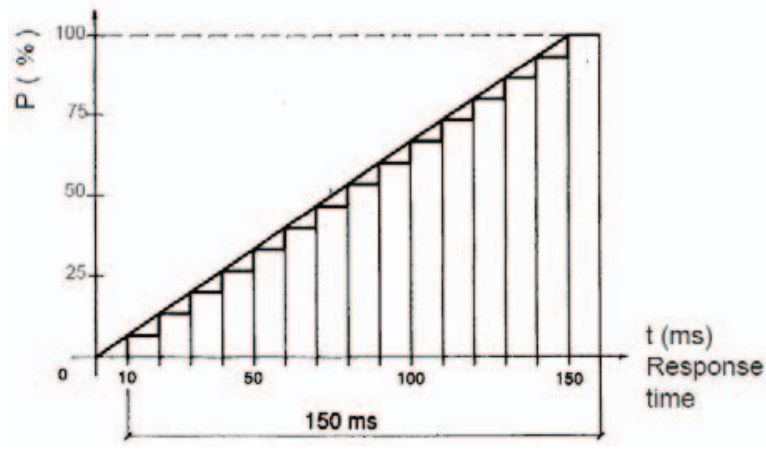

Fig. 9. Dump loads characteristic curve.

At Ngarenanyuki Secondary School, a pair of $2 \mathrm{~kW}$ binary ELC dump loads is installed and each of them has 15 regulating steps of $133 \mathrm{~W}$ [36]. Therefore, the regulation curve can be approximately compared to a straight line. Moreover, as for the recovery time, the dump loads regulator switches from $0 \%$ to $100 \%$ of the regulated power in approximately $150 \mathrm{~ms}$ (Fig. 9). This ELC are fitted with PID $\mu$-controlled frequency system. As a result, the plant frequency changes affect the feedback in function of the entity, duration and speed.

Accordingly, in the MATLAB ${ }^{\circledR}$ Simulink $^{\circledR}$ model the dump loads are constituted by a series of 30 resistors each of regulating power $P_{\text {dump step }}$, which are connected or disconnected in the systems by a PID controller that keeps 
the system frequency at $50 \mathrm{~Hz}$. The PID output represents the electrical power to be dissipated by the dump loads $P_{\text {dump. }}$. An array of 30 Boolean variables $R_{\text {dump status }}$ represents the on-off status of each resistor (3). Hence, after having identified the positional number $i$ of the last activated resistance, a decision about the control action is taken by comparing the current dumped electrical power with $P_{\text {dump }}$ and then by connecting or disconnecting a further resistance, as summarized in Algorithm 1.

$$
R_{\text {status }}=\left[R_{1_{-} 1}, R_{1 \_2}, \cdots, R_{2 \_15}\right]
$$

\begin{tabular}{cl}
\hline ALGORITHM 1: DUMP LOADS CONTROL LOGIC \\
\hline If & $P_{\text {dump_step }} \cdot i<P_{\text {dump }}$ \\
& $R_{\text {dump,status }}(i+1)=1$ \\
Else & $R_{\text {dumpstatus }}(i)=0$ \\
\hline
\end{tabular}

The functioning modelling of the dump load is the main achievement of this first step implementation of the system modellings according to the new approach with regard to the E4G project. Indeed, it is first step for the analysis of the dump load-battery bank coupling.

\section{Loads model}

The loads and the static converter models are developed considering that the electrical dynamics are faster than the mechanical dynamics, and hence the related variables evolve according to a steady-state behavior. Loads and inverters can be modelled as ideal controlled current sources respecting the frequency value from the swing equation and algebraic equations for the power injections.

The input signal, which drives the generated current, is calculated as indicated in (4) where the RMS current value $\left(I_{\text {load }}\right)$ is given by $(5)$ and the frequency $\omega$ results from the swing equation (1):

$$
\begin{aligned}
& I=I_{\text {load }} \sqrt{2} \cdot \sin (\omega \cdot t) \\
& P_{\text {load }}=230 \cdot I_{\text {load }} \cdot \cos (\phi)
\end{aligned}
$$

\section{MODEL VALIDATION THROUGH THE METERED DATA}

The realised model is capable of simulating the operation and dynamic behaviour as regards the power flows among the system components, and to show the frequency trend during the functioning as well. In the follow, a first validation of the model is described.

To validate the system (Fig. 10 and Fig. 11), we exploited the already exposed metered data of the 20 of October, 2014 (Fig. 7):

- The time series of the Banki Turbine power injection $\left(P_{\text {gen }}\right)$ has been considered as exactly metered by the Efficiency Terminal (blue line, Fig. 7).

- The time series of the user loads $\left(P_{\text {load }}\right)$ has been considered as metered by the Efficiency Terminal (green line, Fig. 7) but introducing modification in those parts where clearly a lack of generated power (due to a reduction of the water flow) have brought about also the reduction of the metered load consumption, and hence supposing the load profile to be constant in these periods (green dotted line, Fig. 10). This has been done also to test whether the model returns a frequency trend similar to the metered one.
These two time series represent the input data for the ideal controlled voltage and current sources of the synchronous generator and the load respectively.

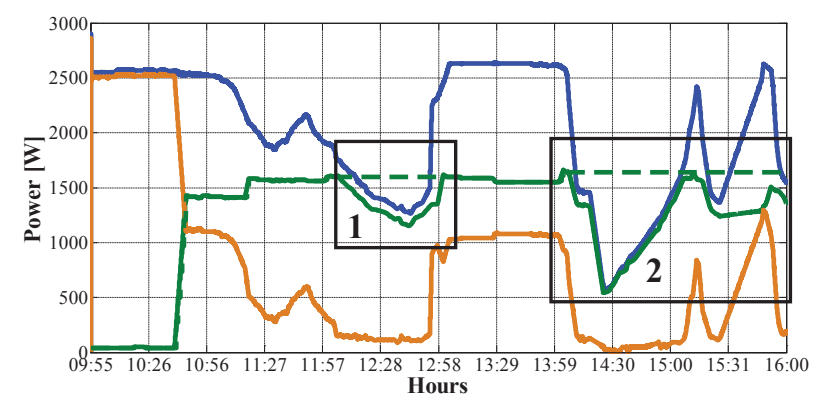

Fig. 10. Power profiles resulting from the system functioning simulation

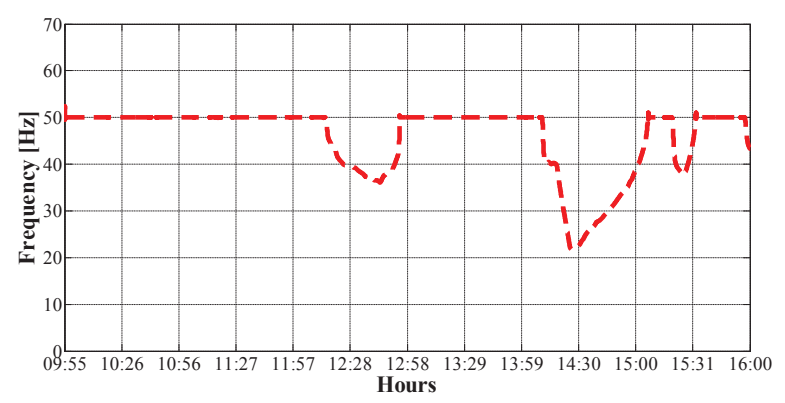

Fig. 11. Frequency resulting from the system functioning simulation.

The results of Fig. 10 and Fig. 11 highlight the proper operating of the model as regards:

- The synchronous generator that set appropriate voltage and current values in order to impose the input power flows time series (blue line, Fig. 10).

- The user loads model that behaves exactly like in the metered case (green line, Fig. 10).

- The dump load model that operates correctly in order to absorb the difference between the injected power by the generator and the required power by the user loads (brown line, Fig. 10).

- The frequency behavior (Fig. 11) that follows the measured profile (red line, Fig. 7), but with a constant difference in those regions in which the frequency is not $50 \mathrm{~Hz}$. This is probably due both to the assumption on the input load profile and to the fact that the current load model does not change its adsorption behaviour according to the variations of the power availability within the power system.

\section{THE NEW APPARATUS: AN HYBRID MICRO-GRID FOR THE NGARENANYUKI SECONDARY SCHOOL}

In conclusion the authors would like to present the proposed architecture of the hybrid MG which will be installed at the Ngarenanyuki Secondary School by mid2015. As already pointed out, this solution aims at modifying the current power supply system by exploiting new power sources, controlling their interactions, and limiting the dissipated energy by adding a storage capacity. The hybrid MG will provide for the parallel functioning of (i) the already present MHP/dump loads group, (ii) the backup petrol generator and (iii) new installations of PV modules and lead-acid batteries together with an Interface Converter. 


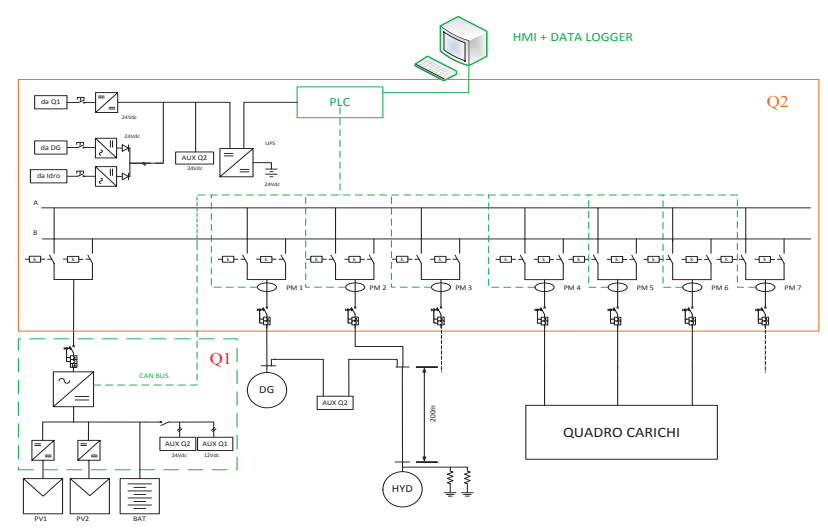

Fig. 12. Hybrid Micro-Grid configuration.

The architecture of the new apparatus (Fig. 12) is composed by: (i) a conversion switchboard (Q1) which considers the new installation of PV and battery bank system and the bi-directional Interface Converter, and (ii) a distribution switchboard (Q2) able to work on two busbars, integrating PLC control system, smart meters, and local user interface in order to manage the power flow control strategies from the power sources. Different operation modes have been considered to set up the control logics:

- Manual mode: the operator can manage the loads connection/disconnection and can select the power generators by acting on different selectors. During this mode the PLC controls subsystem Q1 to realise grid forming operation.

- Automatic mode: the PLC measures voltage, current, frequency, power and manages the system through six configurations:

1. Q1 on-grid, following the MHP. In this operation mode the Banki turbine defines voltage and frequency, while Q1 is controlled in following mode with respect to the hydro turbine. The control board of Q1 implements MPPT algorithm to maximise the power extracted by the PV system. PLC decides also the active and reactive power set points of Q1 on the basis of load requirements, battery SOC and MHP generation.

2. Q1 on-grid, following the petrol generator. This operation mode works like mode 1 but with petrol generator in place of the MHP.

3. Q1 off-grid, forming mode. In this operation the PLC send to the control board of the inverter the set-points of voltage and frequency to be maintained on the grid, and it limits the discharge power of the battery bank by monitoring its SOC.

4. MHP stand-alone mode. This operation mode is activated when the batteries SOC is too low, then the PLC manages the switching of loads according to power production and different priorities.

5. Petrol generator stand-alone mode. This operation mode works like mode 4 but with petrol generator in place of the MHP.

6. Double bus bar mode. This configuration allows the MHP and the petrol generator to work together, each one on a bus-bar. In this case, the Q1 always works following the MHP.
It is worthwhile to mention that the control logics that coordinate the operations and transitions between the different operation modes, brings about issues as regards of power system stability. For this reason experimental tests have been put in place in parallel to the modelling activities exposed in the previous sections. This, in order to test the control logics with regard to the system components reaction times, the rates of change in the power flows that can occur during the system functioning, the real system inertias, etc.
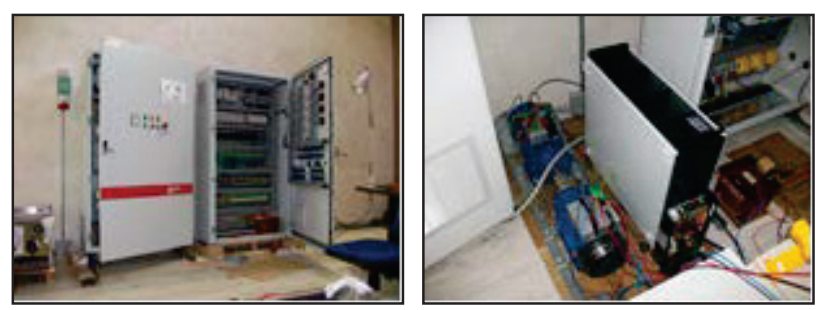

Fig. 13. Q1 and Q2 switchboards - DC motor and ELC dump loads

In particular, the test facilities (Fig. 13) exploit a leadacid battery bank, a PV array emulator, a $2 \mathrm{~kW}$ binary ELC dump loads and a DC motor for emulating the MHP generator. Then, the managing capability of different energy/power flows of Q1 and Q2 have been tested in order to verify the new prototype apparatus response before its final installation at Ngarenanyuki Secondary School.

\section{CONCLUSIONS}

This paper presents the project Energy4Growing that addresses the improvement of the power supply service of the Ngarenanyuki Secondary School (Tanzania) by implementing a hybrid micro-grid. Firstly the functioning of the actual school power supply system (run-off-river MHP plant with dump loads) is described by means of the data gathered during an in-field metering campaign. Then, a new approach that addresses the simulation of the electro-mechanical operation and dynamics within an offgrid power system, with respect to perturbation in the power injections from generators and loads, is introduced. According to the new approach, the development of the synchronous generators, user loads and dump loads models is described. Then, the model of the actual school power system has been implemented and simulated.

The performed simulations highlight the potentiality of the new approach in integrating the aspects of energy analyses and power system stability analyses aiming at better supporting the design process of off-grid power systems. Finally, a brief excursus on the test facilities on the new apparatus, which will be installed at the school, is also exposed.

\section{ACKNOWLEDGMENTS}

The authors would like to thank Roberto Di Molfetta for the support in collecting all the information during the on-field mission at Ngarenanyuki (Sept. and Oct. 2014) 


\section{REFERENCES}

[1] IEA, World Energy Outlook 2014. OECD Publishing, 2014, p. 748.

[2] S. C. Bhattacharyya, "Energy access programmes and sustainable development: A critical review and analysis," Energy Sustain. Dev., vol. 16, no. 3, pp. 260-271, Sep. 2012.

[3] D. P. Kaundinya, P. Balachandra, and N. H. Ravindranath, "Grid-connected versus stand-alone energy systems for decentralized power-A review of literature," Renew. Sustain. Energy Rev., vol. 13, no. 8, pp. 2041-2050, Oct. 2009.

[4] K. Q. Nguyen, "Alternatives to grid extension for rural electrification: Decentralized renewable energy technologies in Vietnam," Energy Policy, vol. 35, no. 4, pp. 2579-2589, Apr. 2007.

[5] X. Liu and B. Su, "Microgrids - An Integration of Renewable Energy Technologies," 2008.

[6] M. Welsch, M. Bazilian, M. Howells, D. Divan, D. Elzinga, G. Strbac, L. Jones, A. Keane, D. Gielen, V. S. K. M. Balijepalli, A. Brew-Hammond, and K. Yumkella, "Smart and Just Grids for sub-Saharan Africa: Exploring options," Renew. Sustain. Energy Rev., vol. 20, pp. 336-352, Apr. 2013.

[7] B. K. Blyden and W. J. Lee, "Holistic Approach for Grid Interconnection in Africa," in Inaugural IEEE PES 2005 Conference and Exosition in Africa, 2005, no. July, pp. 1115.

[8] Schnitzer, Lounsbury, Carvallo, Deshmukh, Apt, and Kammen, Microgrids for Rural Electrification : A critical review of best practices based on seven case studies. United Nations Foundation, 2014.

[9] D. Hill, "Definition and classification of power system stability," pp. 1-15, 2003.

[10] T. Khatib, A. Mohamed, K. Sopian, and M. Mahmoud, "Optimal sizing of building integrated hybrid PV/diesel generator system for zero load rejection for Malaysia," Energy Build., vol. 43, no. 12, pp. 3430-3435, 2011.

[11] S. Upadhyay and M. P. Sharma, "A review on configurations, control and sizing methodologies of hybrid energy systems," Renew. Sustain. Energy Rev., vol. 38, pp. 47-63, Oct. 2014.

[12] A. Kaabeche, M. Belhamel, and R. Ibtiouen, "Sizing optimization of grid-independent hybrid photovoltaic/wind power generation system," Energy, vol. 36, no. 2, pp. 1214-1222, Feb. 2011.

[13] A. Maleki and A. Askarzadeh, "Optimal sizing of a $\mathrm{PV} /$ wind/diesel system with battery storage for electrification to an off-grid remote region: A case study of Rafsanjan, Iran," Sustain. Energy Technol. Assessments, vol. 7, pp. 147-153, Sep. 2014.

[14] H. Jiayi, J. Chuanwen, and X. Rong, "A review on distributed energy resources and MicroGrid," Renew. Sustain. Energy Rev., vol. 12, no. 9, pp. 2472-2483, Dec. 2008. entro la metà del 2015

[15] S. Mandelli, E. Colombo, M. Merlo, and C. Brivio, "A Methodology to Develop Design Support Tools for Standalone Photovoltaic Systems in Developing Countries," vol. 8, no. 6, pp. 778-788, 2014.

[16] T. Lambert, "Micropower System Modeling with HOMER," pp. 379-418.

[17] R. Sen and S. C. Bhattacharyya, "Off-grid electricity generation with renewable energy technologies in India: An application of HOMER," Renew. Energy, vol. 62, pp. 388-398, Feb. 2014
[18] G. Bekele and G. Tadesse, "Feasibility study of small Hydro/PV/Wind hybrid system for off-grid rural electrification in Ethiopia," Appl. Energy, vol. 97, pp. 515, Sep. 2012.

[19] a. T. D. Perera, R. a. Attalage, K. K. C. K. Perera, and V. P. C. Dassanayake, "A hybrid tool to combine multiobjective optimization and multi-criterion decision making in designing standalone hybrid energy systems," Appl. Energy, vol. 107, pp. 412-425, Jul. 2013.

[20] X. Zhang, R. Sharma, and Y. He, "Optimal energy management of a rural microgrid system using multiobjective optimization," Innov. Smart Grid Technol. ..., pp. $1-8,2012$.

[21] J. a. Cherni, I. Dyner, F. Henao, P. Jaramillo, R. Smith, and R. O. Font, "Energy supply for sustainable rural livelihoods. A multi-criteria decision-support system," Energy Policy, vol. 35, no. 3, pp. 1493-1504, Mar. 2007.

[22] J. Glover, M. Sarma, and T. Overbye, Power System Analysis \& Design, SI Version. 2011.

[23] K. Prabha, "Power system stability and control," Editor. Ma Granw-Hill, 1994.

[24] J. Thambirajah, E. Barocio, and N. F. Thornhill, "Comparative review of methods for stability monitoring in electrical power systems and vibrating structures," IET Gener. Transm. Distrib., vol. 4, no. 10, p. 1086, 2010.

[25] S. U. N. Yuanzhang, S. Member, W. Lixin, L. I. Guojie, and L. I. N. Jin, "A Review on Analysis and Control of Small Signal Stability of Power Systems with Large Scale Integration of Wind Power," pp. 1-6, 2010.

[26] J. P. Ramírez, "Review of Methodologies for the Analysis of Voltage Stability in Power Systems," 2013.

[27] P. K. Olulope, "Dynamic Impact and Assessment of Stability of Power Systems with DG Penetration: A Review," 2010.

[28] R. Majumder, "Some Aspects of Stability in Microgrids," IEEE Trans. Power Syst., vol. 28, no. 3, pp. 3243-3252, Aug. 2013.

[29] S. Baudoin, I. Vechiu, and H. Camblong, "A review of voltage and frequency control strategies for islanded microgrid," vol. 33 , no. 0 .

[30] S. Doolla and T. S. Bhatti, "Load Frequency Control of an Isolated Small-Hydro Power Plant With Reduced Dump Load," vol. 21, no. 4, pp. 1912-1919, 2006.

[31] R. Raja Singh, T. Raj Chelliah, and P. Agarwal, "Power electronics in hydro electric energy systems - A review," Renew. Sustain. Energy Rev., vol. 32, pp. 944-959, Apr. 2014.

[32] T. S. Bhatti, A. F. Al-Ademi, and N. K. Bansal, "Load frequency control of isolated wind-diesel-microhydro hybrid power systems (WDMHPS)," Energy, vol. 22, no. 5, pp. 461-470, 1997.

[33] A. F. Zobaa and R. C. Bansal, Handbook of renewable energy technology. World Scientific, 2011.

[34] V. Bisht, Y.. Sood, N. Kushwaha, and Suryakant, "Review On Electronic Load Controller," vol. 102, no. 1, pp. 93102, 2012.

[35] D. Henderson, "An advanced electronic load governor for control of micro hydroelectric generation," IEEE Trans. Energy Convers., vol. 13, no. 3, pp. 300-304, 1998.

[36] IREM, "Electronic regulators and electric control boards," 2014. 